\title{
REVIEW
}

\section{GENDER DISPARITY IN PREVALENCE OF DEPRESSION AMONG PATIENT POPULATION: A SYSTEMATIC REVIEW}

\author{
Kalkidan Hassen Abate ${ }^{1}$
}

\begin{abstract}
BACKGROUND: Many people are unable to withstand the set point for usual vicissitudes of life and are overwhelmed by depression, especially when there is a potential stressor like a disease. Gender is very important in defining susceptibility and exposure to a number of mental health risks. The objective of this review is to systematically identify, appraise and synthesize the best available evidence on gender disparity in prevalence of depression among patient populations.

METHODS: Observational analytical studies done on patients of 18 years old were included. The JBIMAStARI tool for extraction was used to pool quantitative data. Review Manager Software was used for meta-analysis and Odds ratios and their $95 \%$ confidence intervals were calculated.

RESULT: On Meta-analysis, a total of 19639 patients were involved, with male to female ratio of 1.14:1. The finding of the Meta analysis showed that male sex is $63 \%$ less likely to develop depression than female sex (Odds ratio=0.63, 95\% Confidence Interval $=0.59,0.68)$. The studies included were homogenous; Heterogeneity test: $\mathrm{Chi}^{2}=309.23, \mathrm{df}=30,(P<0.00001)$.

CONCLUSION: Depression is more common among females than male patients.

KEYWORDS: Gender disparity, depression, systematic review
\end{abstract}

DOI: http://dx.doi.org/10.4314/ejhs.v23i3.11

\section{INTRODUCTION}

Data on the size of the global burden of mental disorders reveals depression as being a significant and growing public health problem associated with a heavy burden of morbidity and disability in both developed and developing nations (1). There are wide ranges of points of view and perspectives of human psychological construct: as normal facilitating, pathological debilitating, emotional state or reaction, disorder and syndrome (2). The capacity to tolerate a "normal expectable" level of stressor is a sign of optimum mental health (3). However, many people are unable to withstand the set point for usual vicissitudes of life and are overwhelmed by anxiety and depression; as a result, symptoms of depression and/or anxiety may develop. Among all psychiatric disorders, anxiety and depression are the most frequent (1).

\footnotetext{
${ }^{1}$ Department of Biomedical Sciences, Jimma University, Ethiopia Correspondence: kalkidan.hassed@ju.edu.et
}

Gender is one of the critical determinants of health which influences the power and control men and women have over the determinants of their health, including their socioeconomic position, roles, rank and social status, access to resources and treatment in a society (4). As such, gender is important in defining susceptibility and exposure to a number of mental health risks (1). It becomes impossible to examine the impact of gender on mental health without studying existing gender-based disparity in prevalence of depression as baseline data (3). Consequently, the conceptual framework for this review is developed to determine disparity if it exists so that the study can contribute to endeavors of redressing the determinants that lead to poor health.

Many of the negative experiences of and exposures to mental health risk factors that lead to and maintain the psychological disorders predominately involve gender-based socio- 
economic expectations (4). To reduce the contribution of gender in the rise of prevalence of depression among patient population, gender sensitive health care is essential and services must be tailored to meet the needs of each gender.

The literature consistently indicates that both diagnostic syndrome and clinical depression are more prevalent among boys than girls until adolescence, when rates for girls increase while rates for boys stabilize, until the $2: 1$ ratio is established (5). In adulthood, some review showed that women are approximately twice as likely as men are to experience depression. However, findings of disparity on patient population are inconsistent (Table 1)-some favoring the classical finding-more females depressed while others not (Table 1). Thus, this review is done and believed to be helpful to provide the best available evidence on disparity in gender specific prevalence of depression among patient populations.

\section{METHODS}

The objective of this review was to systematically identify, appraise and synthesize the best available evidence on gender disparity in prevalence of depression among patient population by limiting variations of the diagnostic criteria or instrument and enabling similar set of reference for the study population. Studies done on patients of 18 years old or older regardless of country of residence, ailment sustained or comorbid factors were included. Observational analytical studies (cohort studies, case-control studies and cross-sectional studies) only done by Beck depression scale (BDI), Zung Self-Rating Depression Scale (ZUNG SDS), Diagnostic and Statistical Manual of Mental illness (DSM IV), Hospital Anxiety and Depression Scale (HADS), Hamilton Depression Rating Scale (HDRS), The Mini-International Neuropsychiatric Interview (MINI), The Composite International Diagnostic Interview (CIDI), Epidemiological Studies-Depression scale (CES-D), six-item Self-report scale (K6) and
Patient Health Questionnaire 9 (PHQ-9) for depression were considered for inclusion. These scales have been used to assess anxiety more extensively worldwide than any other measures and selected for their validity and reliability on the study setting.

Three staged search strategy was used to identify all relevant published literature in English language from the millennium to 2012. Databases searched were PubMed, CINAHL, PopLine, LILACS, MedNar and Embase. All papers selected for inclusion in the review were subjected to a rigorous, independent appraisal by the investigator prior to inclusion in the review using standardized critical appraisal instruments from the Joanna Briggs Institute (6). Quantitative papers were pooled in statistical meta-analysis using the Review Manager Software (Rev Man 5). Odds ratios and their 95\% confidence intervals were calculated for analysis.

The following search strategy was modified for the various databases and search engines with initial keywords/search terms: ("Depression" OR "Prevalence of depression" OR "Prevalence of anxiety and depression" OR "anxiety", OR "depression) and (Gender difference OR "sex difference" OR "gender"OR "gender disparity”).

\section{RESULTS}

A total of 2450 relevant papers were identified in the literature search and 685 of them were retrieved for examination. Following review of titles and abstracts against the review objectives and inclusion criteria, 569 titles were excluded. The full texts of the remaining 116 studies were retrieved for detailed evaluation, after which, 55 of these were excluded. The remaining 61 studies were assessed for methodological quality using the JBI-MAStARI critical appraisal tool and, subsequently, 31 studies were included in the review for meta-analysis; the other thirty studies were deemed to be of insufficient methodological quality and were excluded from the review. 
Table 1: Summary of main details of the included studies

\begin{tabular}{|c|c|c|c|c|c|c|c|}
\hline Author & year & $\begin{array}{l}\text { Sample } \\
\operatorname{size}(\mathbf{N})\end{array}$ & Tool & $\begin{array}{l}\text { \% Male } \\
\text { depressed }\end{array}$ & $\begin{array}{c}\text { Total } \\
\text { N }\end{array}$ & $\begin{array}{l}\text { \% Female } \\
\text { depressed }\end{array}$ & $\begin{array}{c}\text { Total } \\
\mathbf{N}\end{array}$ \\
\hline Reyes-Zúñigaet al. (7) & 2012 & 382 & HADS & 73 & 236 & 75 & 146 \\
\hline Moussaset al. (8) & 2008 & 132 & BDI & 34 & 78 & 30 & 54 \\
\hline Tselebiset al. (9) & 2010 & 167 & BDI & 73 & 132 & 26 & 35 \\
\hline Li XJ et al. (10) & 2012 & 1059 & HADS & 114 & 914 & 177 & 1081 \\
\hline $\mathrm{Na}$ Yong et al (11) & 2012 & 176 & HADS & 3 & 32 & 28 & 144 \\
\hline Golpouret al. (12) & 2012 & 100 & BDI & 9 & 44 & 44 & 56 \\
\hline Tovillaet al (13) & 2012 & 702 & HDRS & 139 & 310 & 196 & 392 \\
\hline Sulehriet al. (14) & 2010 & 60 & BDI & 31 & 36 & 17 & 24 \\
\hline Nidhinandanaet al. (15) & 2007 & 110 & TGDS & 15 & 38 & 9 & 22 \\
\hline Al Ansari et al.,(16) & 2010 & 300 & MINI & 54 & 130 & 100 & 170 \\
\hline Eiman M., Manal S. (17) & 2004 & 125 & DSM-IV & 10 & 45 & 63 & 80 \\
\hline Arrollet al. (18) & 2009 & 7433 & CIDI & 370 & 4460 & 337 & 2973 \\
\hline Mhaidatet al. (19) & 2009 & 280 & HADS & 29 & 146 & 43 & 134 \\
\hline Zafarullah K. (20) & 2012 & 81 & DSM-IV & 23 & 49 & 8 & 32 \\
\hline Sherinaet al. (21) & 2002 & 188 & DSM-IV & 31 & 117 & 10 & 91 \\
\hline Liang et al. (22) & 2012 & 1144 & Zungscal & 144 & 487 & 237 & 657 \\
\hline Silva et al. (23) & 2011 & 288 & HDRS & 18 & 125 & 48 & 193 \\
\hline Gottlieb et al. (24) & 2004 & 155 & BDI & 78 & 122 & 15 & 33 \\
\hline Darnallet al. (25) & 2005 & 914 & CES-D & 156 & 552 & 106 & 361 \\
\hline Bokhariet al. (26) & 2002 & 154 & HADS & 36 & 115 & 21 & 39 \\
\hline Maharajet al. (27) & 2005 & 734 & Zungscale & 40 & 196 & 429 & 538 \\
\hline Afolabiet al. (28) & 2008 & 250 & ZDS & 29 & 74 & 71 & 176 \\
\hline Onesirosanet al. (29) & 2010 & 200 & BDI & 23 & 69 & 37 & 71 \\
\hline Nabil et al. (30) & 2010 & 347 & K6 & 17 & 120 & 32 & 227 \\
\hline Lesman-Leegte et al. (31) & 2009 & 958 & CES-D & 217 & 603 & 170 & 355 \\
\hline Bhandarkaret al. (32) & 2011 & 353 & HADS & 74 & 190 & 99 & 263 \\
\hline Duttaet al. (33) & 2013 & 476 & PHQ9 & 67 & 195 & 184 & 281 \\
\hline $\begin{array}{l}\text { Monteiro and Aparecida. } \\
\text { (34) }\end{array}$ & 2010 & 114 & HDRS & 50 & 62 & 50 & 52 \\
\hline Agbiret al. (35) & 2010 & 160 & DSM-IV & 10 & 94 & 21 & 66 \\
\hline Hakimshooshtaryet al.(36) & 2007 & 509 & DSM-IV & 261 & 407 & 37 & 102 \\
\hline Freedlandet al. (37) & 2003 & 313 & DSM-IV & 88 & 303 & 136 & 310 \\
\hline
\end{tabular}

On Meta-analysis, a total of 19639 patients were involved, with male to female ratio of $1.14: 1$. Among male patients (10481), 2316 were found to have depression (22\%). On the contrary, 2856 of the total female patients (9158) were found to have depression (31.2\%). The finding of the Meta-analysis showed male sex is $63 \%$ less likely to develop depression than female sex (Odds ratio $=0.63,95 \%$ Confidence Interval $=0.59,0.68$ ). The studies included were homogenous; heterogeneity test: $\mathrm{Chi}^{2}=1.35, \mathrm{df}=2,(\mathrm{P}=0.51)$. The test for overall effect also showed a high statistical significance at conventional levels $(\mathrm{P}<0.000001)$. Thus females are more depressed than males among patient populations. 
Table 2: Meta-analysis of included studies

\begin{tabular}{|c|c|c|c|c|c|c|c|c|c|c|}
\hline \multirow[b]{2}{*}{ Study or Subgroup } & \multicolumn{2}{|c|}{ Experimental } & \multicolumn{2}{|c|}{ Control } & \multirow[b]{2}{*}{ Weight } & \multirow{2}{*}{$\begin{array}{l}\text { Odds Ratio } \\
\mathrm{M} \cdot \mathrm{H} \text {, Fixed, } 95 \% \mathrm{Cl}\end{array}$} & & \multirow{2}{*}{\multicolumn{2}{|c|}{$\begin{array}{c}\text { Odds Ratio } \\
\mathrm{M} \cdot \mathrm{H} \text {, Fixed, } 95 \% \mathrm{Cl}\end{array}$}} & \\
\hline & Events & Total & Events & Total & & & & & & \\
\hline Zafarullah K. & 23 & 49 & 8 & 32 & $0.3 \%$ & $2.65[1.00,7.05]$ & & & & \\
\hline Tselebis et al. & 73 & 132 & 26 & 35 & $1.0 \%$ & $0.43[0.19,0.98]$ & & & & \\
\hline Tovilla et al. & 139 & 310 & 196 & 392 & $5.1 \%$ & $0.81[0.60,1.10]$ & & & & \\
\hline Silva et al. & 18 & 125 & 48 & 193 & $1.7 \%$ & $0.51[0.28,0.92]$ & & 7 & & \\
\hline Sherina et al. & 31 & 117 & 10 & 91 & $0.4 \%$ & $2.92[1.35,6.34]$ & & & & \\
\hline Bokhari et al. & 36 & 115 & 21 & 39 & $1.1 \%$ & $0.39[0.19,0.82]$ & & 7 & & \\
\hline Reyes-Zúñiga et al. & 73 & 236 & 75 & 146 & $3.4 \%$ & $0.42[0.28,0.65]$ & & $\rightarrow$ & & \\
\hline Onesirosan et al. & 23 & 69 & 37 & 71 & $1.3 \%$ & $0.46[0.23,0.91]$ & & & & \\
\hline Nidhinandana et al. & 15 & 38 & 9 & 22 & $0.4 \%$ & $0.94[0.32,2.75]$ & & & & \\
\hline Nabil et al. & 17 & 120 & 32 & 227 & $1.0 \%$ & $1.01[0.53,1.90]$ & & & & \\
\hline Na Yong et al. & 3 & 32 & 28 & 144 & $0.5 \%$ & $0.43[0.12,1.51]$ & & & & \\
\hline Moussas et al & 34 & 78 & 30 & 54 & $1.1 \%$ & $0.62[0.31,1.24]$ & & & & \\
\hline Monteiro and Aparecida. & 50 & 62 & 50 & 52 & $0.6 \%$ & $0.17[0.04,0.78]$ & & & & \\
\hline Mhaidat et al. & 29 & 146 & 43 & 134 & $1.9 \%$ & $0.52[0.30,0.90]$ & & & & \\
\hline Maharaj et al. & 40 & 196 & 429 & 538 & $9.7 \%$ & $0.07[0.04,0.10]$ & & $\mp$ & & \\
\hline LixJ et al & 114 & 914 & 177 & 1081 & $7.6 \%$ & $0.73[0.56,0.94]$ & & $\leftarrow$ & & \\
\hline Lesman-Leegte etal. & 217 & 603 & 170 & 355 & $7.3 \%$ & $0.61[0.47,0.80]$ & & 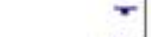 & & \\
\hline Freedland et al. & 88 & 303 & 136 & 310 & $5.1 \%$ & $0.52[0.37,0.73]$ & & $\rightarrow$ & & \\
\hline Liang et al. & 144 & 487 & 237 & 657 & $7.6 \%$ & $0.74[0.58,0.96]$ & & & & \\
\hline Hakimshooshtary et al. & 261 & 407 & 37 & 102 & $1.1 \%$ & $3.14[2.00,4.93]$ & & & 7 & \\
\hline Gottlieb et al. & 78 & 122 & 15 & 33 & $0.5 \%$ & $2.13[0.98,4.63]$ & & & & \\
\hline Golpour et al. & 9 & 44 & 44 & 56 & $1.6 \%$ & $0.07[0.03,0.19]$ & & & & \\
\hline Eiman M., Manal S. & 10 & 45 & 63 & 80 & $1.9 \%$ & $0.08[0.03,0.19]$ & & & & \\
\hline Dutta et al. & 67 & 195 & 184 & 281 & $5.3 \%$ & $0.28[0.19,0.41]$ & & 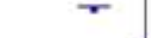 & & \\
\hline Bhandarkar etal & 74 & 190 & 99 & 263 & $2.7 \%$ & $1.06[0.72,1.55]$ & & & & \\
\hline Darnall et al. & 156 & 552 & 106 & 361 & $4.9 \%$ & $0.95[0.71,1.27]$ & & & & \\
\hline Arroll et al. & 370 & 4460 & 337 & 2973 & $19.7 \%$ & $0.71[0.61,0.83]$ & & - & & \\
\hline Sulehri et al. & 31 & 36 & 17 & 24 & $0.2 \%$ & $2.55[0.70,9.28]$ & & & & \\
\hline Al Ansari et al. & 54 & 130 & 100 & 170 & $2.7 \%$ & $0.50[0.31,0.79]$ & & - & & \\
\hline Agbir et al. & 10 & 94 & 21 & 66 & $1.2 \%$ & $0.26[0.11,0.59]$ & & & & \\
\hline Afolabi et al. & 29 & 74 & 71 & 176 & $1.4 \%$ & $0.95[0.55,1.66]$ & & & & \\
\hline Total $(95 \% \mathrm{CI})$ & & 10481 & & 9158 & $100.0 \%$ & $0.63[0.59,0.68]$ & & 1 & & \\
\hline Total events & 2316 & & 2856 & & & & & & & \\
\hline Heterogeneity: $\mathrm{Ch}^{2}=309$ & 2. $d f=30$ & $(P<0.0$ & $0001): 1^{2}$ & $=90 \%$ & & & 0.005 & $0.1 \quad 1$ & $1 \quad 10$ & 200 \\
\hline Test for overall effect: $Z=$ & $2.58(\mathrm{P}<$ & $0.00001)$ & & & & & avours & xperimental & Favours c & \\
\hline
\end{tabular}

\section{DISCUSSION}

The finding of this review is consistent with results of studies conducted across many nations which showed that women are about twice as likely as men to develop depression (38-39). There was no difference identified in disparity in prevalence of depression among patient populations except mimicking the classical finding of general population which is higher prevalence of depression among females. Higher depression disorders among women in general population was noted in studies done by Kessler, McGonagle, Swartz, Blazer, \& Nelson-lifetime prevalence of $21.3 \%$, compared with $12.7 \%$ in men (38-40). The result of this study reflects similarity in men and women's depressive response when both sexes are exposed to stressors.

Even when women and men are confronted with similar stressors, the former may be more vulnerable than the latter to develop depression and related anxiety disorders such as posttraumatic stress disorder (41). Women's greater reactivity compared with men's has been attributed to gender differences in biological responses, selfconcepts, and coping styles. Understanding the gender difference in depression is important for at least two reasons. First, women's high rates of depression incur tremendous costs in quality of life and productivity, for women themselves and their families, so that health care system should give gender sensitive care directed to alleviate the problem. Second, understanding the gender 
difference in depression will help us to understand the causes of depression in general. In this way, gender provides a valuable lens through which to examine basic human processes in psychopathology and psychotherapy.

\section{REFERENCES}

1. World Health Organization. Investing In Mental Health. WHO, Geneva, 2003.

2. David S, Derald S, Stanley S. Understanding Abnormal Behavior, $8^{\text {th }}$ Ed., Houghton Mifflin Company Boston New York.

3. Ahmed M, BadermA. Gender Differences In Anxiety Among Undergraduates From Ten Arab Countries. Social Behavior And Personality, 2004, 32(7), 649-656.

4. World Health Organization. Gender Disparities In Mental Health, WHO, Geneva, 2013.

5. Birmaher B, Ryan N, Williamson D., Brent D., Kaufman J., Dahl R., et al. Childhood and adolescent depression: A review of the past 10 years. J Am Acad Child Adolesc Psychiatry 1996; 35: 1427-1439.

6. The Joanna Briggs Institute. Joanna Briggs Institute Reviewers' Manual: 2008.

7. Reyes-Zuniga M, Castorena-Maldonado A, Carrillo-Alduenda JL, et al., Anxiety And Depression Symptoms In Patients With SleepDisordered Breathing. Open Respir Med J2012;6:97-103.

8. Moussas G, Tselebis A, Karkanias A, et al.A comparative study of anxiety and depression in patients with bronchial asthma, chronic obstructive pulmonary disease and tuberculosis in a general hospital of chest diseases. Annals of General Psychiatry, 2008;7:7.

9. Tselebis A, Kosmas E, Bratis D, Moussas et al.Prevalence of alexithymia and its association with anxiety and depression in a sample of Greek chronic obstructive pulmonary disease (COPD) outpatients Annals of General Psychiatry, 2010; 9:16.

10. Li XJ, He YL, Ma H, et al.Prevalence of depressive and anxiety disorders in Chinese gastroenterological outpatients. World J Gastroenterol. 2012; 18(20): 2561-8.

11. Na Yong, Hua Hu, Xiaoping Fan, et al., Prevalence and risk factors for depression and anxiety among outpatient migraineurs in mainland China. J Headache Pain. 2012; 13(4): 303-310.

12. Golpour M, Hosseini SH, Khademloo M, et al. Depression and Anxiety Disorders among Patients with Psoriasis: A Hospital-Based Case-Control Study. Dermatol Res Pract.2012:381905. 10.1155/2012/381905. Epub 2012 Jul 16.

13. Tovilla-Zárate C, Juárez-Rojop I, Peralta J., et al. Prevalence of Anxiety and Depression among Outpatients with Type 2 Diabetes in the Mexican Population. Plos ONE 2012;7(5): e36887. Doi:10.1371/journal.pone.0036887.

14. Sulehri MA, dogari A, Ahmad I., et al.Prevalence of Depression among Tuberculosis Patients. A.P.M.C., 2010;4;2

15. Nidhinandana S, Chinvarun Y, Sithinamsuwan $\mathrm{P}$, et al. Prevalence of depression among epileptic patients at PramongkutklaoHospital.J Med Assoc Thai 2007; 90: 32-6.

16. Al Ansari A, Hamadeh R, Ali M, et al., Treatment and Prevalence of Generalized Anxiety Disorder and Depression among Primary Care Attendees. Bahrain Medical Bulletin, 2010; 32:1.

17. Eiman M, ManalS. Prevalence of Depression among Kuwaiti Patients Attending the Sawaber Health Center. Kuwait Medical Journal 2004;36 (2): 113-116.

18. Arroll B. Goodyear-Smith F., Kerse N. et al. The prevalence of depression among Maori patients in Auckland general practice. J Primary Health Care 2009; 1(1):26-29.

19. Mhaidat N, Alzoubi K, Al-Sweedan, Alhusein B. Prevalence of depression among cancer patients in Jordan: a national survey. Support Care Cancer (2009) 17:1403-1407.

20. Zafarullah K. Depression among stroke patients and relation with demographic and stroke characteristics (Thesis). Umeå International School of Public Health, Epidemiology and Global Health Autumn. 2011.

21. Sherina MS, Jefferelli SB, Zurani N, Yahaya N. Prevalence of Depression Among Elderly Patients Attending a Primary Health Care Clinic. Malaysian Journal of Psychiatry ,2002;10:2. 
22. Liang JJ, Huang H, Yang B, et al. A crosssectional survey on the prevalence of anxiety symptoms in Chinese patients with premature ventricular contractions without structural heart disease. Chin Med J 2012; 125(14):2466-71.

23. Silva D, Sultan S, Georgin-Lavialle S, et al.Depression in Patients with Mastocytosis: Prevalence, Features and Effects of Masitinib Therapy. Plos ONE 2011; 6(10): e26375. Doi:10.1371/journal.pone.0026375.

24. Gottlieb S, Khatta M., Friedmann E., et al., The influence of age, gender, and race on the prevalence of depression in heart failure patients. J Am CollCardiol. 2004; 43(9):15421549.

25. Darnall BD, Ephraim P, Wegener ST, et al. Depressive symptoms and mental health service utilization among persons with limb loss: result of a national survey. Arch Phys Med Rehabil 2005;86:650-8.

26. Bokhari SS, Samad AH, Hanif S, et al. Prevalence of depression in patients with coronary artery disease in a tertiary care hospital in Pakistan. J Pak Med Assoc 2002; 52(9):436-9.

27. Maharaj RG, Reid SD, Misir A, Simeon DT: Depression and its associated factors among patients attending chronic disease clinics in southwest Trinidad. West Indian Med J, 2005;54:369-37.

28. Afolabi MO, Abioye-Kuteyi EA, Fatoye F O. et al., Pattern of depression among patients in a Nigerian family practice population. SA FamPract 2008;50(2):63.

29. Onesirosan B, Ohiole J, Eze G. Depression among patients with diabetes mellitus in a Nigerian teaching hospital. SAJP, 2010;16:2.

30. Nabil S, Aisha $\mathrm{H}$, Hani $\mathrm{T}$, et al. The prevalence and correlates of depression and anxiety in a sample of diabetic patients in Sharjah, United Arab Emirates, BMC Family Pract 2010;11:1-7.

31. Lesman L, Dirk J, Hans L, et al. Depressive symptoms and outcomes in patients with heart failure: data from the $\mathrm{COACH}$ study. Eur. $J$. Heart Fail. 2009; 11:1202-1207.
32. Bhandarkar PN, Mohd. S. Adinatesh KV et al., Assessment of Anxiety and Depression among Patients Admitted in Tertiary Care Hospital, Karimnagar . Int J Biol Med Res. 2011; 2(4): 1035 - 1037.

33. Dutta D, Bharati S, Roy C, Das G. Measurement of prevalence of 'major depressive syndrome' among Indian patients attending pain clinic with chronic pain using PHQ-9 scale. J AnaesthesiolClinPharmacol 2013;29:76-82.

34. Monteiro S, Aparecida S. Frequency of depression among patients with neuro cysticercosis. ArqNeuropsiquiatr 2010;68(1):76-80.

35. Agbir M., Audu D., Adelbowale T. Goar G. Depression among medical out patients with diabetis. Annals of African Medicine; 2010;9:1,5-10.

36. Hakimshooshtary M. Alagheband $\operatorname{rad} J$. Sharifi, V. et al., Profile of Major Depressive Disorder Symptoms among Patients in Tehran. Iran J Psychiatry 2007; 2: 35-41.

37. Freedland K., Rich W., Skala J., et al. Prevalence of depression in hospitalized patients with congestive heart failure, Psychosom Med 652003 119-128.

38. Kessler R, McGonagle K, Swartz M, Blazer D, Nelson C. Sex and depression in the National Comorbidity Survey. I: Lifetime prevalence, chronicity and recurrence. J Affect Disord 1993;29:85-96.

39. Weissman M, Bland R, Joyce P, Newman S, Wells J, Wittchen H. Sex differences in rates of depression: cross-national perspectives. J Affect Disord 1993;29:77- 84.

40. Kornstein S. The evaluation and management of depression in women across the life span. $\mathbf{J}$ Clin Psychiatry, 2001; 62(24):11-7.

41. Breslau N. Glenn C. Patricia A, et al., Sex Differences in Posttraumatic Stress Disorder Arch Gen Psychiatry. 1997;54(11):1044-1048. 